\title{
Meteorology
}

\section{Origins of stony-iron meteorites}

\author{
from Edward R.D. Scott
}

AlTHOUGH most of the meteorites that fall on Earth are chondrites, more is known about the formation and parent bodies of the 15 per cent that come from bodies that were once largely molten. Three such igneous meteorites come from the surface of the Moon ${ }^{1}$, eight may have come from Mars $^{2}$, and a large group - known as basaltic achondrites - may be pieces of 4 Vesta, the second or third largest asteroid $^{3,4}$. But what is the origin of the variety of igneous meteorites known as stony-irons, which account for only seven per cent of falls of igneous meteorites but whose unusual mineralogy constitutes a major puzzle? New astronomical and theoretical studies indicate how and where the stony-iron meteorites may have formed in the asteroid belt.

Most igneous meteorites contain either less than $1 \%$ or greater than $99 \%$, by weight, of metallic iron-nickel and other metallic phases. This is because the large density difference between molten iron and silicate ensures their rapid separation. By con-trast, stony-irons usually contain $40-60 \mathrm{wt} \%$ iron-nickel (and always 20-80 wt \%). In pallasites, the remainder is olivine $(\mathrm{Mg}, \mathrm{Fe})_{2} \mathrm{SiO}_{4}$, whereas in mesosiderites it is basaltic material, which lacks significant amounts of olivine.

How were large volumes of metal intimately mixed with massive amounts of mantle olivine or crustal basalts? For the pallasites, it is widely believed that metal from the core of a molten asteroid was forced into part of the surrounding olivine mantle as a result of cooling stresses, impacts and the weight of the mantle. But it is much more difficult to understand how mesosiderites formed. Petrological studies show that brecciated basaltic material from the surface of an asteroid was mixed with metallic iron-nickel without the inclusion of significant quantities of mantle olivine. At $1,000^{\circ} \mathrm{C}$, the cooling rate of the mixture was about one degree per year but because the mesosiderites were eventually buried so deeply, their rate of cooling at $500^{\circ} \mathrm{C}$ was reduced by at least $10^{5}$-fold and so was slower than that of any other type of meteorite.

Conventional models for the origin of mesosiderites attribute the mixing of metal and silicate to impacts between two igneously differentiated asteroids, and the slow cooling to subsequent accretion. However, R. Greenberg and C.R. Chapman $^{5}$ argue that the lack of olivine, the uniform cooling rates and the abundance of mesosiderites preclude such models and suggest instead that the mixing occurred within a single asteroid. In their scheme, a solid basaltic crust of a largely molten body sank towards the core-mantle interface

when it was fractured by impacts because it was slightly denser than a liquid mantle beneath it. Liquid iron from the core penetrated the cold fractured blocks of crust so that the mixture cooled rapidly at high temperatures but much more slowly at low temperatures. Greenberg and Chapman suggest that pallasites formed in smaller bodies in which the olivine-rich mantles solidified before the crusts foundered.

Reviewing this and other proposed origins for mesosiderites, R. Hewins ${ }^{6}$ concludes that no single model is wholly satisfactory. He finds that mesosiderite textures resemble those of rocks formed by impacts and believes that major collisions must have mixed metal and silicate. Hewins suggests that mesosiderites lack olivine because, unlike all known oxidized chondrites, their parent body never contained much olivine - an argument not favored by Greenberg and Chapman.

There has been no certain identification of asteroids with mesosiderite-like surfaces, although several S-type asteroids have been proposed as candidates. However, recent telescopic observations have revealed the existence of a new class of asteroids with surfaces that resemble those

\section{Shiro Kakiuchi 1929-1984}

SHIRO Kakiuchi of Osaka University Medical School, who died on 22 September, was a pioneer in many areas of cell regulation. During the mid 1960s he worked with T. E. Rall at Case Western Reserve in Ohio and made many contributions to cyclic nucleotide research during the formative years of this field. It was during this time that he began work on cyclic nucleotide phosphodiesterases. In 1970, soon after his return to Japan, Dr Kakiuchi revealed that a form of phosphodiesterase required the presence of an activator and that stimulation by the activator required $\mathrm{Ca}^{2+}$-dependent protein activator that later came to be called calmodulin.

Kakiuchi realized the potential importance of the activator in other enzyme systems and in 1978 recognized that it was also the activator of myosin light chain kinases. Subsequently he isolated the protein from a variety of ciliates and invertebrates and discovered a calmodulindependent form of guanylate cyclase. In the same year, Kakiuchi found that calmodulin was partitioned between the soluble and particulate fractions of the cell, which led him to the discovery in 1980 that the only calmodulin-binding protein in the cytoskeleton of the red blood cell is spectrin. A year later he was the first to show the of pallasites. According both to D.P. Cruikshank and W.K. Hartmann ${ }^{7}$ and to J.F. Bell and coworkers ${ }^{8}$, infrared spectra of 246 Asporina, 289 Nenetta and 446 Aeternitas show the deep absorption bands of olivine and overall red colors that are consistent with the presence of a metal phase. Hence some asteroids of $50-100 \mathrm{~km}$ diameter have melted to form olivine-rich mantles that have since been exposed by collisional stripping of the crusts.

To learn more about the origins of mesosiderites and pallasites we must reach a much better understanding of the nature and distribution of the heat source, and of the movement of solid and liquid phases during melting and solidification. We need to know whether totally molten mantles of olivine-rich composition could be produced, and whether melting occurred after or during accretion in the asteroid belt. Theory and experiment will help to address these questions but to understand fully the origins of stony-irons we shall also need field studies of asteroids.

1. Eberhardt, J. Science News 126, 70 (1984)

2. McSween, H.Y. Jr, Geology 12, 3 (1984)

. Drake, M.J. in Asteroids (ed. Gehrets, T.) 765 (University of Arizona, 1979)

Chapman, C.R. Planetary Report 4, 12 (1984)

. Greenberg, R. \& Chapman, C.R. Icarus 57, 267 (1984).

6. Hewins, R.H. J. geophys. Res. Suppl. 88, B257 (1983).

Cruikshank, D.P. \& Hartmann, W.K. Science 223, 281 (1984).

8. Bell, J.F., Hawke, B.R., Singer, R.B. \& Gaffey, M.J. in Lunar and Planetary Science XV, 48 (Lunar and Planetary Institute, Houston 1984).

Edward R,D. Scott is in the Institute of Meteoritics, University of New Mexico, Albuquerque, New Mexico 87131. presence of a spectrin-like protein in other tissues and to purify the protein from brain. Also in 1981 he purified another calmodulin-binding protein from chicken smooth muscle and showed that it interacted with actin filaments.

This protein, which he called caldesmon, was subsequently named fodrin by US scientists. Caldesmon interacts with actin when the $\mathrm{Ca}^{2+}$ concentration is less than $1 \mu \mathrm{M}$ but with calmodulin at higher concentrations. This led to the hypothesis that calmodulin might control those proteins associated with actin in a 'flip-flop' mechanism depending on the $\mathrm{Ca}^{2+}$ concentration. The hypothesis was later extended to the $\mathrm{Ca}^{2+}$ regulation of microtubules when Kakiuchi showed that one of the microtubule-associated proteins, tau, was a $\mathrm{Ca}^{2+}$-dependent calmodulin binding protein.

All of these experiments were pioneering efforts and each observation has been repeated and extended by numerous laboratories. As much as any one individual Shiro Kakiuchi was the father of the field of calmodulin research and an innovator in the study of its interaction with other regulatory proteins. He will be passionately missed by his many students, collaborators and friends.

A.R. Means 